\title{
Exploratory Case-Control Analysis of Psychosocial Factors and Adult Periodontitis
}

Mark E. Moss, ${ }^{*}$ James D. Beck, ${ }^{\dagger}$ Berton H. Kaplan,${ }^{\dagger}$ Steven Offenbacher, ${ }^{\dagger}$ Jane A. Weintraub, ${ }^{\ddagger}$ Gary G. Koch, ${ }^{\dagger}$ Robert J. Genco, ${ }^{\S}$ Eli E. Machtei,${ }^{\S}$ and Lisa A. Tedesco ${ }^{\|}$

WE EXPLORED THE ASSOCIATION between social factors and adult periodontitis by comparing self-reported information for daily strains and symptoms of depression in 71 cases and 77 controls. Cases and controls were selected from among 1,426 participants in the Erie County Risk Factor Study. We found differences among those who scored higher than their peers on measures of social strain. The odds ratio (OR) and $95 \%$ confidence interval $(95 \% \mathrm{CI})$ for the association between case status and Role Strain score of 2.27 or more was $2.84,95 \% \mathrm{CI}=1.08$ to 7.46 . We also examined serum antibody, dichotomized at the median, for three periodontal pathogens (Bacteroides forsythus [IgG Bf], Porphyromonas gingivalis [IgG Pg], Actinobacillus actinomycetemcomitans [IgG $A a]$ ), and assessed interaction between antibody levels and a Depression score derived from the Brief Symptom Inventory. IgG $\mathrm{Pg}$ and IgG $\mathrm{Aa}$ were both strongly associated with case status $(\mathrm{OR}=4.52,95 \% \mathrm{CI}=1.99$ to 10.3 and $\mathrm{OR}=5.29,95 \% \mathrm{CI}=2.34$ to 12.0 , respectively). $\mathrm{IgG} B f$ was associated with periodontal disease but only among individuals who had higher scores for Depression ( $\mathrm{OR}=6.75,95 \% \mathrm{CI}=1.25$ to 36.5$)$. Smoking status was associated with case status $(\mathrm{OR}=4.95,95 \% \mathrm{CI}=1.86$ to 13.2$)$. We assessed these findings prospectively by examining factors associated with more extensive disease among the 71 case subjects after 1 year of follow-up. We found baseline smoking status and IgG Bf among individuals scoring high on Depression at baseline to be associated with more extensive disease ( $8.1 \%$ or more of the sites showing further breakdown). In this population an elevated Depression score may be a marker for social isolation, which could play a role in immune function during periods of social strain. This exploratory analysis has served to identify specific lines of inquiry concerning psychosocial measures as important environmental factors in adult periodontitis. J Periodontol 1996;67:1060-1069.

Key Words: Depressive disorder; depression; periodontitis/etiology; stress; social environment.

Periodontal disease is a broad term for a family of chronic infectious disease processes variously described to affect $5 \%$ to $36 \%$ of the adult U.S. population, depending on the measure of disease applied. ${ }^{1}$ Adult periodontitis is known to vary by race, education level, and gender, suggesting that factors related to the social environment may be important in disease development. ${ }^{2}$ While researchers have identified factors related to endocrine and immune

\footnotetext{
*Eastman Dental Center, Rochester, NY.

'University of North Carolina, Chapel Hill, NC.

*University of California, San Francisco, CA.

${ }^{\S}$ State University of New York at Buffalo, NY.

"University of Michigan, Ann Arbor, MI.
}

function as well as a subset of microorganisms that appear to play a role in periodontal disease, less has been done to establish host factors related to the social environment that influence disease progression.

Since the 1950s, emotional factors have been identified in periodontal disease ${ }^{3}$; however, many studies relating these factors to periodontal conditions have been limited to one specific type of periodontitis, acute necrotizing ulcerative gingivitis, which may differ substantially from other forms of periodontal disease. ${ }^{4}$

Recently, attention by some investigators has been directed toward adult periodontitis and psychosocial factors which may influence disease activity. Marcenes and Shei- 
ham examined periodontal health status with respect to work stress and marital quality in 149 males aged 35 to $44 .^{5}$ Work stress and marital quality were measured by using a series of questions administered in an interview in the subjects' homes. Higher scores for work-related mental demand were associated with pocketing and/or gingivitis as were low scores in marital quality. Freeman and Goss reported preliminary results of work done in a follow-up study of 10 employed women and eight employed men having a mean age of 39 years. ${ }^{6}$ These authors were able to investigate periodontal attachment loss occurring over a 12-month period in incisors and first molars. The authors found a relationship between increase in pocket depth and scores for Type A personality and a measure for lack of information concerning changes in the workplace.

Conceptually, adult periodontitis represents the endpoint that results from the interplay between one or more of a series of bacterial challenges and the response of a host's immune system occurring over time. Social strains and psychosocial factors related to social support and coping may be important in adult periodontal disease activity if these factors influence the immune response to infection.

The aim of the present study was to explore the role of psychosocial factors including social strain, depression, and coping as host factors that influence adult periodontitis with the use of self-reported questionnaire data. We employed a case-control approach and exploratory analytical techniques to identify associations of adult periodontitis with social strains and depression symptoms. We also explored joint effects between depression symptoms and antibody level for three periodontal pathogens with respect to case status. We then assessed these factors prospectively among the 71 cases by using disease status data collected at a 1-year follow-up examination.

\section{MATERIALS AND METHODS}

\section{Subject Selection}

To focus attention on host factors related to disease progression, we sought to identify individuals with active periodontal disease as cases and to compare these cases with individuals having less severe disease. Cases were defined as individuals who met the baseline criteria for established periodontitis as described by Machtei et al. ${ }^{7}$ and who also demonstrated further attachment loss at a 1-year follow-up examination. The baseline criteria for established periodontitis were as follows: two or more interproximal sites from different teeth with clinical attachment level of $6 \mathrm{~mm}$ or greater and at least one additional site with a pocket depth of $5 \mathrm{~mm}$ or greater. $^{7}$ Controls were selected from those who did not meet the criteria for established periodontitis at both baseline and a 2-year follow-up examination. Measurements used to define disease status were performed with an electronic probe known to be more sensitive than a manual probe for measuring periodontal attachment level. ${ }^{8}$ Controls were chosen randomly from among potential referents with similar age group, gender, and race group distributions as the case group.

All subjects were selected from the Erie County Risk Factor Study conducted by investigators at the State University of New York at Buffalo. The study subjects were primarily white residents of greater Buffalo, Erie County, New York. The Erie County Risk Factor Study is an ongoing follow-up study, comprised of two cohorts that arose from a single cross-sectional sample of 1,426 adults.

One cohort (the adult periodontitis cohort) arising from the cross-sectional sample is made up of 100 individuals who met the case definition for history of adult periodontitis. This cohort is being seen at 3-month intervals by the Buffalo investigators. At the time of this analysis, 79 individuals had completed 1 year of follow-up. All 79 of the available subjects in the adult periodontitis cohort make up the case group.

The control sample was selected from a disease-free cohort of study subjects aged 25 to 74 years also initially enrolled in the cross-sectional sample of the Erie County Risk Factor Study. This cohort is made up of 400 individuals initially chosen as a disease-free cohort for follow-up at a 2-year interval. At the time of control selection, 188 individuals from this group of 400 had completed the follow-up examination.

The selection process for controls involved stratification of the age-race-gender distribution of the cases, such that cases and controls would have similar distributions without being matched one to one. Of the 79 cases, 72 described their race as white. We selected seven controls with race other than white, which covered the age distribution of the seven cases with race other than white fairly well. These seven cases had an age range of 36 to 64 with a mean of 50.6 years. Their selected controls' age range was 40 to 71 with a mean of 51.1 years. By gender, five of these seven cases were male while only three of the seven selected controls were male. By race, six of these cases were black while five of the selected controls were black.

Among the white race group we selected 78 controls for 72 cases. We over-sampled referents slightly among whites such that each age-gender-specific cell had at least four controls whenever the corresponding cell had at least one case in it. In the group of 164 individuals selected for inclusion in the analyses, $150(91.5 \%)$ reported their race as white, $11(6.7 \%)$ reported their race as black, and $3(1.8 \%)$ were classified as race groups other than white or black. Overall, the mean age (standard deviation) for cases was 44.4 (8.6) years and for controls 43.8 (9.3) years. Since there were only seven cases with race other 
than white (and seven corresponding controls as described above), we assessed the effect of race by running the analyses with all participants and with only white participants. The results of these analyses were similar and only the results using all race groups are presented.

\section{Questionnaire-Based Measures}

Questionnaires were self-administered to assess daily strains, measures of psychological distress, and coping style. The Daily Strains Scale is based on work by Pearlin and Schooler. ${ }^{9}$ Strains are addressed in five social domains (Job Strain, Financial Strain, Spouse Strain, Strain of Being Single, and Strain Related to Parenting Children) and one global domain termed Role Strain. Individuals are asked to indicate their level of agreement with statements or how frequently conditions occur in each of the five social domains. For example, one item asks, "Do you have more work than you can handle?" and respondents select from "Never or almost never," "Once in a while," "Much of the time," or "Almost always." These responses are coded 1-4 respectively, and an average score is calculated for each domain for each participant. Subjects were asked to respond only to items which applied to them; that is, those subjects who were unemployed at the time of the survey were requested to skip questionnaire items related to Job Strain.

The Brief Symptom Inventory-an abbreviated version of the SCL-90-R-was used to measure psychological distress. ${ }^{10}$ Subjects were asked to rate how much discomfort was experienced over the past week for each of 53 items on a 5-point scale (0-4) from "not at all" $(0)$ to "extreme" (4). The Brief Symptom Inventory provides an assessment of psychological symptoms in nine areas: anxiety, somatization, interpersonal sensitivity, psychoticism, paranoid ideation, depression, hostility, phobic anxiety, and obsessive-compulsive. A score for each symptom area is derived from responses for four to seven items. Anxiety reflects feelings of fear, nervousness, and restlessness. Somatization reflects distress arising from bodily complaints (dizziness, hot spells, weakness, etc.). Interpersonal sensitivity assesses problems associated with self-image (feeling inferior, being easily hurt, etc.). Psychoticism can reflect severe psychotic thought patterns; however, in many samples, the authors of the inventory state that psychoticism is more a measure of alienation. ${ }^{11}$ Paranoid ideation reflects a high degree of suspiciousness (i.e., people will take advantage of you if you let them). Depression reflects feelings of loneliness and worthlessness. Hostility reflects the tendency toward confrontation (easily irritated, feeling urges to break things, etc.). Phobic anxiety reflects fears and uneasiness associated with unfamiliar surroundings. Obsessive-compulsive reflects cognitive functioning difficulties (trouble remembering things, difficulty making decisions, etc.).

Coping style was assessed by using the COPE inven- tory. ${ }^{12}$ This instrument assesses the different ways people respond to stress and provides summaries on two broad scales: problem-focused coping and emotion-focused coping. Problem-focused coping can be described as a coping style which is aimed at solving problems as they arise. People who score high on the problem-focused coping scale generally respond to stressful situations by taking action. Emotion-focused coping is aimed at reducing or managing the emotional distress associated with a disturbing situation. Emotion-focused coping tends to predominate when a situation must be endured. While most stressful situations elicit both types of coping styles to some degree, the COPE instrument identifies the style an individual uses most often.

\section{Clinical Examination}

All subjects were examined at the State University of New York at Buffalo Periodontal Disease Research Clinic. After completing an institution-approved consent form, a medical screening questionnaire, and psychosocial questionnaires described above, a clinical dental examination was performed in a separate dental examination room. The medical screening questionnaire was primarily used to identify individuals in need of premedication with antibiotics because of the risk of endocarditis resulting from the dental examination. For each tooth present, calibrated examiners performed assessments of supragingival plaque, gingival bleeding, subgingival calculus, probing depth, and clinical attachment level. Probing depth and clinical attachment level were measured with the use of a constant-force electronic periodontal probe equipped with a computerized measurement recording system. ${ }^{8}$ For each individual, mean values were calculated from the tooth-specific values. These measurements have been described previously. ${ }^{7}$

Screening for specific microorganisms was performed by collection of subgingival plaque and immunofluorescence. ${ }^{13}$ Two pooled subgingival plaque samples were collected for each participant. Each pooled sample was made up of six mesiobuccal samples collected with paper points; one pooled sample came from six maxillary teeth and one came from six mandibular teeth. Using immunofluorescence, the following microorganisms were assessed: Actinobacillus actinomycetemcomitans, Bacteroides forsythus, Campylobacter rectus, Capnocytophaga species, Eubacterium saburreum, Fusobacterium nucleatum, Porphyromonas gingivalis, and Prevotella intermedia. An individual was considered to be infected if the organism made up $1 \%$ or more of the colonies counted. It was felt that the false-positive detection rate would be kept low by requiring an organism to make up at least $1 \%$ of the colonies counted. ${ }^{13}$ 
Table 1. Descriptive Variables for Individuals With Complete Data on Daily Strains Scales

\begin{tabular}{lccc}
\hline Attribute & $\begin{array}{c}\text { All Subjects } \\
(\mathrm{n}=148)\end{array}$ & $\begin{array}{c}\text { Cases } \\
(\mathrm{n}=71)\end{array}$ & $\begin{array}{c}\text { Controls } \\
(\mathrm{n}=77)\end{array}$ \\
\hline $\begin{array}{l}\text { Gender } \\
\% \text { male }\end{array}$ & 64.2 & 66.2 & 62.3 \\
$\quad \begin{array}{l}\text { Age } \\
\% \text { 25-34 }\end{array}$ & 20.3 & 14.1 & \\
$\%$ 35-44 & 39.2 & 39.4 & 26.0 \\
$\quad \%$ 45-74 & 40.5 & 46.5 & 38.9 \\
Smoking status & & & \\
$\quad \%$ current smokers & 25.7 & 38.0 & 14.3 \\
Household income & & & \\
$\quad \%$ \$30,000 or more & 54.1 & 47.9 & 59.7 \\
\% above median for IgG: & & & \\
$\quad \begin{array}{l}\text { A. actinomycetemcomitans } \\
\text { B. forsythus }\end{array}$ & 50.7 & 73.2 & 29.9 \\
P. gingivalis & 51.4 & 50.7 & 52.0 \\
\hline
\end{tabular}

\section{Laboratory Assays.}

Venous blood samples were obtained from each subject by using evacuated blood collection tubes (without anticoagulant). Subjects were requested to refrain from eating for the prior 8-hour period. Standard blood chemistry measures such as total cholesterol, albumin, glucose, and uric acid levels were determined enzymatically by standard methods with an automatic analyzer."

Antibody assays were performed for three putative periodontal disease pathogens: A. actinomycetemcomitans, $P$. gingivalis, and $B$. forsythus. Serum antibody is conceptually a measure of disease activity which may be more sensitive than clinical observation and may serve to identify host susceptibility or initiation of disease. ${ }^{14} \mathrm{We}$ dichotomized each antibody at the median for each organism. For immunoglobulin $\mathrm{G}(\mathrm{IgG})$ to $P$. gingivalis the median was 4.77 (range 1.62 to 76.17 ). For IgG to $A$. actinomycetemcomitans it was 5.63 (range 1.07 to 62.13). For IgG to $B$. forsythus the median was 22.85 (range 2.38 to 554.55 ).

\section{Exploratory Data Analysis}

We used the approach outlined by Wartenberg and Northridge $^{15}$ to explore various cut-points for defining "exposure." This approach involves graphing of percentile distributions by case status for continuous or scaled variables which cover a range of values. The approach allows an exhaustive summarization of the data and is well suited for generation of hypotheses concerning threshold levels. We sought to describe the conditions where case status varied most by social strain category, by symptom level, and by coping style. We also examined whether income level and coping style were important effect modifiers in the social strain-case status relationships and whether antibody level was an important effect modifier for the re-

"CPF/MetPath Laboratories, Williamsville, NY. lationship between case status and Depression score, since these relationships have been identified as related to one another in other contexts. ${ }^{16,17}$

In this paper, we present results that suggest patterns. The intent of this analytic approach was to identify leads for further investigation. Results are presented as odds ratios (ORs) with corresponding $95 \%$ confidence intervals (CIs) as measures of association derived from logistic regression.

Findings that appeared strong were considered further in an analysis of prospective data for individuals followed for 1 year. A total of 79 individuals who met the baseline definition for established periodontitis were seen at quarterly intervals for a 1-year period. We used data collected from the final examination to identify individuals with more extensive disease activity in terms of the proportion of sites that went on to develop more attachment loss. Attachment loss at a site was assessed as loss in attachment beyond the site-specific threshold outlined below.

The approach used to establish threshold levels for periodontal attachment loss at a given site is described by Machtei et al. ${ }^{18}$ For each patient, 12 individualized thresholds were developed based upon tooth type (molar or other), site location (buccal or lingual), and probing depth (0 to $3.9 \mathrm{~mm}, 4.0$ to $6.9 \mathrm{~mm}, 7.0 \mathrm{~mm}$ or greater). Each patient's thresholds for attachment loss were calculated by using standard deviations derived from repeated measurements made at sites at the final (12-month) examination and corrected for overall measurement error. This approach allows for lower thresholds in shallow sites where measurement error is less and higher thresholds in deep sites where measurement error is greater.

\section{RESULTS}

There were 71 cases and 77 controls with complete data on Daily Strain measures. Table 1 shows the distribution of cases and controls by selected demographic variables. 
Table 2. Description of Questionnaire-Based Responses to Psychosocial Scales by Case Status (Range, Mean and Standard Deviation (SD) Is Provided for Each Subscale)

\begin{tabular}{|c|c|c|c|c|}
\hline Attribute $(\mathrm{N})$ & - Range & $\begin{array}{l}\text { Mean for } \\
\text { Cases (SD) }\end{array}$ & $\begin{array}{c}\text { Mean for } \\
\text { Controls (SD) }\end{array}$ & $P$-Value* \\
\hline \multicolumn{5}{|l|}{ Daily Strains Scale } \\
\hline Job Strain (134) & $1.2-3.2$ & $2.17(0.38)$ & $2.14(0.39)$ & 0.48 \\
\hline Financial Strain (147) & $1.0-4.0$ & $2.00(0.75)$ & $1.83(0.79)$ & 0.14 \\
\hline Spouse Strain (112) & $1.1-3.8$ & $1.90(0.57)$ & $1.88(0.58)$ & 0.71 \\
\hline Being Single Strain (58) & $1.0-3.4$ & $1.66(0.48)$ & $2.05(0.63)$ & 0.06 \\
\hline Children Strain (97) & $1.2-3.3$ & $1.88(0.39)$ & $1.78(0.40)$ & 0.26 \\
\hline Role Strain (148) & $1.0-3.4$ & $1.99(0.39)$ & $1.95(0.39)$ & 0.32 \\
\hline \multicolumn{5}{|l|}{ Coping Style } \\
\hline Problem-focused Coping (135) & $6-18.8$ & $13.2(2.71)$ & $13.6(2.64)$ & 0.30 \\
\hline Emotion-focused Coping (135) & $6-16.5$ & $11.6(2.35)$ & $11.7(2.34)$ & 0.57 \\
\hline \multicolumn{5}{|l|}{ Brief Symptom Inventory } \\
\hline Anxięty (148) & $0-3.5$ & $0.48(0.64)$ & $0.47(0.55)$ & 0.73 \\
\hline Somatization (148) & $0-2.7$ & $0.28(0.46)$ & $0.30(0.48)$ & 0.73 \\
\hline Interpersonal Sensitivity (147) & $0-3.5$ & $0.44(0.67)$ & $0.65(0.78)$ & 0.24 \\
\hline Psychoticism (148) & $0-2.6$ & $0.31(0.58)$ & $0.34(0.47)$ & 0.90 \\
\hline Paranoid Ideation (148) & $0-3.0$ & $0.44(0.63)$ & $0.62(0.63)$ & 0.25 \\
\hline Depression (148) & $0-3.8$ & $0.47(0.77)$ & $0.47(0.63)$ & 0.70 \\
\hline Hostility (148) & $0-3.8$ & $0.44(0.73)$ & $0.41(0.44)$ & 0.48 \\
\hline Phobic Anxiety (148) & $0-3.2$ & $0.20(0.52)$ & $0.19(0.46)$ & 0.71 \\
\hline Obsessive-Compulsive (148) & $0-3.5$ & $0.65(0.68)$ & $0.75(0.60)$ & 0.39 \\
\hline
\end{tabular}

*Adjusted for age, sex, and current smoking status.

There was a slightly higher proportion of male cases than male controls. Cases were generally older than controls and much more likely to be current smokers.

Table 2 presents the data for measures of the Daily Strains Scale and the Brief Symptom Inventory. In general, the means and standard deviations for cases are similar to those for controls. After adjustment for age, sex, and smoking status differences, there were no strong differences in means between cases and controls. There is a suggestion that cases generally scored higher than controls on the Financial Strain scale and a suggestion that controls scored higher than cases on the Being Single Strain scale. Note that the sample size varies from scale to scale depending on the number of respondents. That is, only individuals who considered themselves to be single completed the Being Single scale items.

In Table 3 the results are presented for "exposure" thresholds determined by plotting the data in percentile comparison graphs. These "exposure" thresholds represent exploratory levels that appear to maximize the differences between cases and controls across the distribution of the Strain Scale or Brief Symptom Inventory variable under consideration. For Job Strain, when the data were dichotomized at scores of 2.0 or greater versus less than 2.0 , the data showed a marked difference between the proportion of cases above 2.0 and the proportion of controls above 2.0 as reflected by the odds ratio. In Table 3 the odds ratios are adjusted for age, sex, and current smoking status. In general, the greatest differences for variables presented in Table 3 were Job Strain, Financial Strain, Role Strain, and Interpersonal Sensitivity. Cases were more likely to have high scores for these three social strain measures and less likely to have high scores for Interpersonal Sensitivity.

Since our focus was on the social strain variables, we examined these in more detail, keeping case status as the dependent variable. We incorporated other variables into Job Strain-case status logistic regression models, Financial Strain-case status models, and Role Strain-case status models. We tested interaction terms for income level and each of the three strain variables in separate models, since income may differentially influence the magnitude of the social strain-case status association. In Table 4 , the association between case status and the dichotomized Job Strain, Financial Strain, and Role Strain variables is stratified by income level. Results from three separate models are presented, each having different sample sizes. In each model, adjustment is made for age, sex, and current smoking status. For each strain measure, the association between having a high score and being classified as a case was stronger among individuals reporting their annual income to be below $\$ 30,000$. The difference in the association between case status and strain measure when the data are stratified by income level was most striking for Financial Strain. For Job Strain, the difference in point estimates for the OR was minimal across income, and the confidence intervals suggest that the relationship between Job Strain and case status does not vary by income level. Role Strain, a global measure of social strain, reflects a combination of the effects observed for Financial Strain and Job Strain.

Similar to Table 4, Table 5 presents the association between social strain measures and case status stratified by emotion-focused coping score. For each of the three mod- 
Table 3. Dichotomized Psychosocial Variables and Odds Ratios Comparing Adult Periodontitis Cases With Controls

\begin{tabular}{|c|c|c|c|c|}
\hline Attribute $(\mathrm{N})$ & $\begin{array}{l}\text { Cutpoint } \\
\text { for } \\
\text { "Exposure" }\end{array}$ & $\begin{array}{c}\% \\
\text { Cases } \\
\text { "Exposed" }\end{array}$ & $\begin{array}{c}\% \\
\text { Controls } \\
\text { "Exposed" }\end{array}$ & $\begin{array}{c}\text { Adjusted Odds } \\
\text { Ratio* }(95 \% \mathrm{CI})\end{array}$ \\
\hline \multicolumn{5}{|l|}{ Daily Strains Scale } \\
\hline $\begin{array}{l}\text { Job Strain (134) } \\
\text { Financial Strain (147) } \\
\text { Spouse Strain (112) } \\
\text { Being Single Strain (58) } \\
\text { Children Strain (97) } \\
\text { Role Strain (148) }\end{array}$ & $\begin{array}{l}2.0 \text { or more } \\
2.5 \text { or more } \\
2.19 \text { or more } \\
2.0 \text { or more } \\
1.91 \text { or more } \\
2.27 \text { or more }\end{array}$ & $\begin{array}{l}76.1 \\
24.3 \\
30.2 \\
30.0 \\
40.4 \\
22.5\end{array}$ & $\begin{array}{l}59.7 \\
13.0 \\
32.2 \\
42.9 \\
28.0 \\
11.7\end{array}$ & $\begin{array}{l}2.33(1.06-5.16) \\
1.91(0.75-4.87) \\
0.91(0.38-2.19) \\
0.68(0.20-2.28) \\
1.76(0.70-4.42) \\
2.84(1.08-7.46)\end{array}$ \\
\hline \multicolumn{5}{|l|}{ Coping Style } \\
\hline $\begin{array}{l}\text { Problem-focused Coping } \\
\text { (135) } \\
\text { Emotion-focused Coping } \\
(135)\end{array}$ & $\begin{array}{l}15.0 \text { or less } \\
10.75 \text { or less }\end{array}$ & $\begin{array}{l}77.6 \\
40.3\end{array}$ & $\begin{array}{l}72.1 \\
32.4\end{array}$ & $\begin{array}{l}1.25(0.55-2.85) \\
1.24(0.57-2.70)\end{array}$ \\
\hline \multicolumn{5}{|l|}{ Brief Symptom Inventory } \\
\hline $\begin{array}{l}\text { Anxiety (148) } \\
\text { Somatization (148) } \\
\text { Interpersonal Sensitivity } \\
\quad(147)\end{array}$ & $\begin{array}{l}0.83 \text { or more } \\
0.29 \text { or more } \\
1.0 \text { or more }\end{array}$ & $\begin{array}{l}19.7 \\
36.6 \\
11.3\end{array}$ & $\begin{array}{l}16.9 \\
39.0 \\
30.3\end{array}$ & $\begin{array}{l}1.34(0.55-3.27) \\
0.98(0.48-2.00) \\
0.33(0.13-0.86)\end{array}$ \\
\hline Psychoticism (148) & 0.8 or more & 11.3 & 15.6 & $0.81(0.30-2.22)$ \\
\hline Paranoid Ideation (148) & 1.4 or more & 9.9 & 15.6 & $0.67(0.23-1.99)$ \\
\hline Depression (148) & 0.83 or more & 22.5 & 20.8 & $1.28(0.56-2.95)$ \\
\hline Hostility (148) & 0.8 or more & 16.9 & 19.5 & $1.01(0.42-2.44)$ \\
\hline Phobic Anxiety (148) & 0.6 or more & 9.9 & 11.7 & $1.10(0.36-3.34)$ \\
\hline Obsessive-Compulsive (148) & 1.1 or more & 19.7 & 20.8 & $0.93(0.40-2.17)$ \\
\hline
\end{tabular}

*Adjusted for age, sex, and current smoking status.

Table 4. Odds Ratios for Association Between Social Strain Measure and Case Status Stratified by Income

\begin{tabular}{|c|c|c|c|c|}
\hline Model $(\mathrm{N})$ & $\begin{array}{l}\text { Income Below } \\
\$ 30,000\end{array}$ & $\begin{array}{l}\text { 95\% Confidence } \\
\text { Interval }\end{array}$ & $\begin{array}{c}\text { Income at or } \\
\text { Above } \\
\$ 30,000\end{array}$ & $\begin{array}{l}95 \% \text { Confidence } \\
\text { Interval }\end{array}$ \\
\hline Job Strain Model* (134) & 2.55 & $0.71-9.17$ & 2.09 & $0.73-5.98$ \\
\hline Financial Strain Model ${ }^{\ddagger}(147)$ & 4.03 & $1.06-15.4$ & 0.63 & $0.14-2.81$ \\
\hline Role Strain ModeI ${ }^{\ddagger}(148)$ & 4.16 & $1.16-14.9$ & 1.10 & $0.21-5.94$ \\
\hline
\end{tabular}

*Job Strain Model includes terms for age, sex, current smoking status, income, Job Strain and Job Strainincome interaction.

'Financial Strain Model includes terms for age, sex, current smoking status, income, Financial Strain and Financial Strain-income interaction.

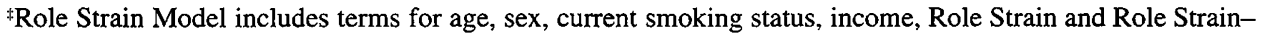
income interaction.

Table 5. Odds Ratios for Association Between Social Strain Measure and Case Status Stratified by Emotion-Focused Coping Score

\begin{tabular}{lcccc}
\hline & $\begin{array}{c}\text { Emotion- } \\
\text { Focused } \\
\text { Score 10.75 } \\
\text { or Less }\end{array}$ & $\begin{array}{c}\text { 95\% } \\
\text { Confidence } \\
\text { Interval }\end{array}$ & $\begin{array}{c}\text { Emotion- } \\
\text { Focused } \\
\text { Score Above } \\
10.75\end{array}$ & $\begin{array}{c}95 \% \\
\text { Confidence } \\
\text { Interval }\end{array}$ \\
\hline Job Strain Model* (122) & 1.07 & $0.29-3.89$ & 4.24 & $1.42-12.7$ \\
Financial Strain Model ${ }^{\dagger}(134)$ & 0.45 & $0.09-2.15$ & 4.35 & $1.15-16.4$ \\
Role Strain Model ${ }^{\ddagger}(135)$ & 0.75 & $0.18-3.09$ & 16.7 & $1.94-144.0$ \\
\hline
\end{tabular}

*Job Strain Model includes terms for age, sex, current smoking status, coping, Job Strain and Job Straincoping interaction.

'Financial Strain Model includes terms for age, sex, current smoking status, coping, Financial Strain and Financial Strain-coping interaction.

${ }^{\ddagger}$ Role Strain Model includes terms for age, sex, current smoking status, coping, Role Strain and Role Straincoping interaction. 
Table 6. Odds Ratios for Association Between Case Status and Role Strain Score

\begin{tabular}{lcc}
\hline Model $^{*}(\mathrm{~N})$ & Odds Ratio & $\begin{array}{c}95 \% \text { Confidence } \\
\text { Interval }\end{array}$ \\
\hline Model 1 (148) & 2.84 & $1.08-7.46$ \\
Model 2 $(147)$ & 2.55 & $0.95-6.82$ \\
Model 3* (148) & 3.56 & $1.14-11.1$ \\
Model 4\$ (148) & 2.57 & $0.85-7.73$ \\
Model 5" (148) & 3.01 & $0.79-11.5$ \\
\hline
\end{tabular}

*All models adjusted for age, sex, current smoking status.

"Model 2 includes plaque score term.

${ }^{\ddagger}$ Model 3 includes depression, $B f$ antibody, and depression- $B f$ antibody interaction terms.

${ }^{\$}$ Model 4 includes terms for $B f$ antibody, $A a$ antibody, and $P g$ antibody. "Model 5 includes terms for depression, $B f$ antibody, $A a$ antibody, $P g$ antibody, and depression- $B f$ antibody interaction.

els presented, the association between social strain and case status was strongest among individuals who were characterized as more. commonly using an emotion-focused style of coping.

Table 6 presents the results for separate models using different variables to assess their impact on the association between Role Strain and adult periodontitis status. Note that one individual was missing data on the plaque score variable so that model 2 has only 147 individuals represented. The point estimates for the OR for the association between a Role Strain score of 2.27 or greater and adult periodontitis are similar across models. The 95\% CIs exclude 1.0 in models 1 and 3. Model 2 differs from model 1 by inclusion of a term for plaque score. Comparing the results from model 1 with those from model 4 allows assessment of the potential for confounding due to measures of antibody for periodontal pathogens on the relationship between case status and Role Strain. Comparing model 2 to model 1 and model 4 to model 1 , the point estimates for the ORs drop slightly when terms for plaque score or serum antibody measures are added, suggesting that Role Strain may not be independent of plaque bacteria or of antibody level in the relationship with case status. However, this may also be interpreted as a representative demonstration of the variability in the Role Strain-case status association. This change in OR estimate when antibody measures are added to a model can be seen when models 5 and 3 are compared as well. The OR for the association between Role Strain and case status ranges from about 2.6 to 3.6 across models. Overall, the results of the five models provide assurance that the association between case status and Role Strain is not explained completely by other factors modeled.

Table 7 presents OR estimates for the association between case status and current smoking status, plaque scores, and antibody levels for A. actinomycetemcomitans and $P$. gingivalis, respectively. Since the sample size was small relative to the number of variables being examined, care was taken to specify a variety of models with different combinations of variables. Therefore, this table pre-
Table 7. Odds Ratios for Association Between Selected Variables and Case Status Generated from Separate Models

\begin{tabular}{lcc}
\hline Model $^{*}(\mathrm{~N})$ & Odds Ratio & $\begin{array}{c}95 \% \text { Confidence } \\
\text { Interval }\end{array}$ \\
\hline Current Smoker (148) & 4.95 & $1.86-13.2$ \\
Plaque Score (147) & 1.16 & $0.57-2.39$ \\
$\mathrm{Aa}$ antibody (148) & 5.29 & $2.34-12.0$ \\
$P g$ antibody (148) & 4.52 & $1.99-10.3$ \\
\hline
\end{tabular}

*All models include terms for age, sex, current smoking status, Role Strain, and variable listed.

sents results from different models that were representative of the estimates obtained from models with different combinations of variables.

Individuals who reported that they currently smoked cigarettes were much more likely to be cases than individuals who did not currently smoke. Cases and controls did not differ greatly by plaque score: among cases $57 \%$ had mean plaque scores above the median (i.e., 0.75 or more); among controls this corresponded to $45 \%$. Antibody levels were dichotomized at the median as stated in the Methods section. For both A. actinomycetemcomitans and $P$. gingivalis, the $\mathrm{OR}$ estimates indicated a strong relationship with case status.

We explored effect modification by Depression score for the relationship between case status and antibody level for each of the three organisms studied. For antibody to both $A$. actinomycetemcomitans and $P$. gingivalis, there was no difference in the stratum-specific point estimates when the data were stratified by dichotomized Depression score. The estimates for the association between antibody to $B$. forsythus and case status are presented in Table 8 , stratified by Depression score, where a high Depression score is defined as 0.83 or greater and low is less than 0.83 . Strong associations are found between $B$. forsythus antibody and case status among individuals with high Depression scores but not among individuals with low Depression scores. This observation, that the association between case status and $B$. forsythus antibody response varies by Depression score, suggests a psychoimmunologic link between $B$. forsythus and adult periodontitis.

\section{One-Year Follow-Up Assessment}

We performed an assessment of our cross-sectional findings among 71 individuals followed in a longitudinal component of the Erie County Risk Factor Study. Of the 79 individuals, 78 in this cohort went on to experience further disease activity, and 71 had complete data for the variables of interest. We used a cutpoint $\geq 8.7 \%$ of sites showing further breakdown, the 70th percentile, to identify a group of 22 individuals with more extensive disease activity relative to the 49 individuals with less extensive disease. The mean proportion of sites showing further disease activity for those classified as having more extensive disease was 12.4 (standard deviation 2.3). Among indi- 
Table 8. Odds Ratios for Association Between IgG B. forsythus Level and Case Status Stratified by Depression Symptom Score

\begin{tabular}{lcccc}
\hline Model (N) & $\begin{array}{c}\text { Depression } \\
\text { Score "Low" }\end{array}$ & $\begin{array}{c}\text { 95\% Confidence } \\
\text { Interval }\end{array}$ & $\begin{array}{c}\text { Depression } \\
\text { Score "High" }\end{array}$ & $\begin{array}{c}\text { 95\% Confidence } \\
\text { Interval }\end{array}$ \\
\hline Base Model* (148) & 0.74 & $0.34-1.63$ & 6.75 & $1.25-36.5$ \\
Job Strain Model ${ }^{*}(134)$ & 0.88 & $0.38-2.03$ & 8.19 & $1.32-51.0$ \\
Income Strain Model I $^{\ddagger}(147)$ & 0.68 & $0.30-1.52$ & 9.19 & $1.39-60.9$ \\
Role Strain Model $(148)$ & 0.68 & $0.30-1.51$ & 7.54 & $1.29-44.0$ \\
\hline
\end{tabular}

*Base Model adjusted for age, sex, and current smoking status.

Job Strain Model adjusted for age, sex, current smoking status, and Job Strain.

*Income Strain Model adjusted for age, sex, current smoking status, and Income Strain.

${ }^{\S}$ Role Strain Model adjusted for age, sex, current smoking status, and Role Strain.

Table 9. Odds Ratios for Association Between Extensive Disease Activity and Factors Explored Among 71 Individuals Followed for One Year

\begin{tabular}{lccccccc}
\hline & $\begin{array}{c}\text { Percent } \\
\text { with } \\
\text { Extensive } \\
\text { Disease } \\
(\mathrm{n}=22)\end{array}$ & $\begin{array}{c}\text { Percent } \\
\text { without } \\
\text { Extensive } \\
\text { Disease } \\
(\mathrm{n}=49)\end{array}$ & $\begin{array}{c}\text { Crude } \\
\text { Odds } \\
\text { Ratio }\end{array}$ & $95 \%$ CI & $\begin{array}{c}\text { Odds } \\
\text { Ratio* }\end{array}$ & $95 \%$ CI \\
\hline Attribute & 54.5 & 28.6 & 3.00 & $1.06-8.52$ & 5.45 & $1.56-19.0$ \\
\hline $\begin{array}{l}\text { Current smoker at base- } \\
\text { line }\end{array}$ & & 12.2 & 2.69 & $0.76-9.56$ & 5.28 & $1.17-23.8$ \\
$\begin{array}{l}\text { High } B \text {. forsythus anti- } \\
\text { body and High De- } \\
\text { pression Score }\end{array}$ & 27.3 & 44.9 & 1.77 & $0.64-4.91$ & 3.56 & $1.03-12.3$ \\
$\begin{array}{l}\text { Income at or above } \\
\$ 30,000\end{array}$ & 59.1 & 10.2 & 2.59 & $0.66-10.1$ & 4.47 & $0.90-22.3$ \\
$\begin{array}{c}\text { Role Strain score at or } \\
\text { above } 2.39 \text { at baseline }\end{array}$ & 22.7 & & & & & \\
\hline
\end{tabular}

*Adjusted odds ratios and corresponding confidence intervals derived from logistic regression. The adjusted estimates for smoking status at baseline, high IgG for $B$. forsythus-high depression score at baseline, and income were derived from the same model with only those terms. The adjusted estimate for Role Strain score of 2.39 or more was derived from a model which also included smoking status at baseline and income level.

viduals classified as having less extensive disease, the mean was 4.0 (standard deviation 2.1).

Information generated from the baseline data was used to explore relationships with extensive disease activity. The estimates from the follow-up assessment are presented in Table 9. We found that individuals who were current smokers at the baseline examination were more likely to experience extensive disease activity during the 1-year follow-up period. Individuals who had elevated levels of antibody to $B$. forsythus and scored high on the Depression scale were also more likely to experience extensive disease activity; however, this was only statistically significant when income level was included as a covariate, along with current smoking status.

None of the social strain variables, as dichotomized in the cross-sectional analysis, showed a relationship with more extensive disease activity. However, when Role Strain scores were examined in a percentile comparison graph, there was a suggestion that cases with more extensive disease activity differed from cases with less extensive disease activity at a Role Strain score cut-point of 2.39. This level was more extreme than the cut-point of 2.27 used to classify individuals as having Role Strain in the cross-sectional analysis. The OR for the association between more extensive disease activity and a Role Strain score of 2.39 or greater at baseline was 4.47 ( 0.90 to 22.3 ) when variables for smoking status and income were included as covariates. The width of the confidence interval around the adjusted point estimate and the observation that the crude OR was much lower (2.59) raise some doubts concerning the effect of social strains on extent of further disease activity. However, in keeping with the spirit of exploratory data analysis, this result is reported so readers may draw their own conclusions.

\section{DISCUSSION}

In this exploratory analysis, our goal was to take some steps towards increasing our understanding of psychosocial factors and adult periodontitis. In the cross-sectional data, we found associations between measures of social strain and case status. We found an association between elevated level of IgG for $B$. forsythus and case status among individuals who scored higher than their peers on levels of Depression. In addition to these findings, measures of smoking status and antibody for A. actinomycetemcomitans and $P$. gingivalis were higher in cases than 
controls, which is in agreement with other studies of periodontal disease. However, in assessing these results in the cohort of 71 individuals classified as prevalent cases at baseline, we were able to draw only limited assurance that these findings were associated with a greater proportion of sites showing further disease activity. Elevated serum $B$. forsythus antibody among individuals with higher scores for Depression and a Role Strain score of 2.39 or greater at baseline were factors that suggest a need for further evaluation, given the limited sample size.

The presence of a biologic gradient in an exposuredisease relationship is one factor which strengthens the argument that the relationship is causal. That is, as exposure increases, a greater proportion of diseased individuals should be observed if the exposure indeed causes the disease. This idea of a dose-response relationship in the context of social factors and disease has been identified in some studies but not others. ${ }^{19}$ Cassel has questioned whether the criterion of a biologic gradient applies to social factors and health since a greater number of social relationships also imply a greater number of social responsibilities, such that, beyond a certain point, more is not necessarily better. ${ }^{20}$ Likewise, regarding social strains, a certain level of social strain is likely to accompany most people and may indeed be a marker for a full, active, healthy lifestyle. However, a threshold level of social strain may be present such that negative physiologic effects result in pathology. These lines of reasoning imply that identification of threshold levels for dichotomization of continuous or ordinal scales is desirable.

These results should be interpreted in terms of the scientific literature pertinent to each comparison, keeping in mind the cross-sectional nature of the data and the potential for measurement error in subjective assessment of psychosocial information. Cross-sectional data are limited, in that, temporal relationships among factors are unknown and, therefore, cause and effect cannot be determined. It is unclear, for example, whether a self-report of high amounts of social strain results from disease or whether disease results from social strain in the crosssectional analyses. We attempted to clarify the temporal relationship between variables by examining the 71 individuals followed for 1 year. While some of the results were suggestive, a larger sample would allow control for potential confounding factors.

Self-reported, personal information which may be perceived as sensitive is difficult to collect. Respondents may under-report or over-report or choose not to participate. Also, individual perceptions of social strain and measures of physiologic distress may not equate such that one person may readily report high levels of strain but be functioning at a very healthy level, while another individual may report low levels of strain but be experiencing a great deal of physiologic distress.

The finding that higher scores for depression may have a role in adult periodontitis is of interest since it may be linked to factors related to social isolation in this sample. Social isolation has been observed to be important in a number of studies of health. In mortality studies, it has been shown that social isolation is associated with reduced survival ${ }^{21-27}$ (also see 28 for review). And in studies of immune function, loneliness, bereavement, and divorce have been found to be related to physiologic parameters such as poor lymphocyte proliferative response, elevated antibody to latent herpes virus, and lower natural killer cell activity. ${ }^{17,29-31}$

The conceptual framework that identifies social support as a buffer for health effects associated with social strain has been in the epidemiologic literature for over 20 years and is periodically expanded and revisited. ${ }^{20,28.32}$ In 1972 , Nuckolls et al. ${ }^{33}$ assessed the relationship between psychosocial assets, social stresses, and pregnancy outcomes. These authors pointed out several methodological issues, including the need to assess the balance between factors that exacerbate socially stressful situations and factors which offset potential insult due to negative environmental stimuli. Over a variety of disease states and health conditions, there have been inconsistent results when this conceptual framework is applied, ${ }^{19}$ especially in the area of infectious disease. ${ }^{29,31.34}$ Adult periodontitis may offer a better fit of the paradigm since cumulative effects of pathology are readily observable, and investigators do not need to rely on the temporal proximity of the social strain event to identify an effect related to health status; i.e., periodontal attachment level is generally not regained once it is lost, thereby serving as a record for past disease activity.

Our findings are consistent with adult periodontitis serving as a model for studies which seek to establish the relationship between psychosocial factors and chronic infectious disease activity in observational studies. For relevant psychosocial factors, we found individuals with prevalent disease to report higher levels of social strain than individuals without prevalent adult periodontitis. We also found a strong relationship between prevalent disease and elevated antibody level to $B$. forsythus to exist only among individuals with greater evidence of depression than their peers.

As emphasized by Kaplan et al., ${ }^{32}$ a hallmark of epidemiologic research is its effort to uncover patterns shared by people in terms of social characteristics or circumstances. However, the social environment for any given individual is a complex web of opportunities and constraints. Our ability to measure the impact of this environment on human health and specifically immune function is understandably limited. For these reasons an exploratory approach to self-reported levels of social strain and psychological distress and their relationship to immune activity is appropriate and desirable. Our assessment of the ability of social factors to predict the extent 
of disease experienced by 71 individuals followed for 1 year leaves many questions unanswered. It will be up to further investigations to substantiate these exploratory findings.

\section{Acknowledgments}

This research was supported by NIDR grants T32 DE07191 and DE04898.

\section{REFERENCES}

1. Brown LJ, Oliver RC, Löe H. Periodontal diseases in the U.S. in 1981: Prevalence, severity, extent, and role in tooth mortality. $J$ Periodontol 1989;60:363-370.

2. Oliver RC, Brown LJ, Löe H. Variations in the prevalence and extent of periodontitis. J Am Dent Assoc 1991;122:43-48.

3. Moulton R, Ewen S, Thieman W. Emotional factors in periodontal disease. Oral Surg Oral Med Oral Pathol 1952;5:833-860.

4. Melnick SL, Roseman JM, Engel D, Cogen RB. Epidemiology of acute necrotizing ulcerative gingivitis. Epidemiol Rev 1988;10:191211.

5. Marcenes WS, Sheiham A. The relationship between work stress and oral health status. Soc Sci Med 1992;35:1511-1520.

6. Freeman R, Goss S. Stress measures as predictors of periodontal disease-a preliminary communication. Community Dent Oral Epidemiol 1993;21:176-177.

7. Machtei EE, Christersson LA, Grossi SG, Dunford R, Zambon JJ, Genco RJ. Clinical criteria for the definition of "established periodontitis." J Periodontol 1992;63:207-215.

8. Clark WB, Yang MC, Magnusson I. Measuring clinical attachment: Reproducibility of relative measurements with an electronic probe. J Periodontol 1992;63:831-838.

9. Pearlin LI, Schooler C. The structure of coping. J Health Soc Behav 1978;19:2-21.

10. Derogatis LR, Cleary PA. Confirmation of the dimensional structure of the SCL-90: A study in construct validation. J Clin Psychol 1977;33:981-989.

11. Derogatis LR, Melisaratos N. The Brief Symptom Inventory: An introductory report. Psychol Med 1983;13:595-605.

12. Carver CS, Scheier MF, Weintraub JK. Assessing coping strategies: A theoretically based approach. J Pers Soc Psychol 1989;56:267283.

13. Bonta Y, Zambon JJ, Neiders M, Genco RJ. Rapid identification of periodontal pathogens in subgingival plaque: Comparison of indirect immunofluorescence microscopy with bacterial culture for detection of Actinobacillus actinomycetemcomitans. J Dent Res 1985;64:793799.

14. Ebersole JL, Holt SC. Immunological procedures for diagnosis and risk assessment in periodontal diseases. In: Johnson NW, ed. Risk Markers for Oral Diseases. Cambridge: Cambridge University Press; 1991;3:203-227.
15. Wartenberg D, Northridge M. Defining exposure in case-control studies: A new approach. Am J Epidemiol 1991;133:1058-1071.

16. Pearlin LI. The sociological study of stress. J Health Soc Behav 1989;30:241-256.

17. Kiecolt-Glaser JK, Glaser R. Stress and immune function in humans. In: Ader R, Felten DL, Cohen N, eds. Psychoneuroimmunology. 2nd ed. San Diego: Academic Press, Inc.; 1991:849-867.

18. Machtei EE, Norderyd J, Koch G, Dunford R, Grossi S, Genco RJ. The rate of periodontal attachment loss in subjects with established periodontitis. J Periodontol 1993;64:713-718.

19. Broadhead WE, Kaplan BH, James SA, et al. The epidemiologic evidence for a relationship between social support and health. Am J Epidemiol 1983;117:521-537.

20. Cassel J. The contribution of the social environment to host resistance. Am J Epidemiol 1976;104:107-123.

21. Schoenbach VJ, Kaplan BH, Fredman L, Kleinbaum DG. Social ties and mortality in Evans County, Georgia. Am J Epidemiol 1986;123: $577-591$

22. Berkman LF, Syme SL. Social networks, host resistance and mortảlity: A nine-year follow-up study of Alameda County residents. Am J Epidemiol 1979;109:186-204.

23. House JS, Robbins C, Metzner HL. The association of social relationships and activities with mortality: Prospective evidence from the Tecumseh Community Health Study. Am J Epidemiol 1982;116: 123-140.

24. Blazer DG. Social support and mortality in an elderly community population. Am J Epidemiol 1982;115:684-694.

25. Welin L, Tibblin G, Svardsudd K, et al. Prospective study of social influences on mortality. Lancet 1985;1:915-918.

26. Reed D, McGee D, Yano K, et al. Social networks and coronary heart disease among Japanese men in Hawaii. Am J Epidemiol 1983;117:384-396.

27. Rubberman W, Weinblatt E, Goldberg JD, et al. Psychosocial influences on mortality after myocardial infarction. $N$ Engl $J$ Med 1984;311:552-559.

28. Berkman LF. Social networks, support, and health: Taking the next step forward. Am J Epidemiol 1986;123:559-562.

29. Cohen S, Williamson GM. Stress and infectious disease in humans. Psychol Bull 1991;109:5-24.

30. Kiecolt-Glaser JK, Glaser R. Psychoneuroimmunology: Can psychological interventions modulate immunity? J Consult Clin Psychol 1992;60:569-575.

31. Sheridan JF, Dobbs C, Brown D, Zwilling B. Psychoneuroimmunology: Stress effects on pathogenesis and immunity during infection. Clin Microbiol Rev 1994;7:200-212.

32. Kaplan BH, Cassel JC, Gore S. Social support and health. Med Care 1977;15(suppl.):47-58.

33. Nuckolls KB, Cassel J, Kaplan BH. Psychosocial assets, life crisis and the prognosis of pregnancy. Am J Epidemiol 1972;95:431-441.

34. Peterson PK, Chao CC, Molitor T, et al. Stress and pathogenesis of infectious disease. Rev Infect Dis 1991;13:710-720.

Send reprint requests to: Dr. Mark E. Moss, Eastman Dental Center, 625 Elmwood Avenue, Rochester, NY 14620. 